\title{
The Valuation of Genetic Diversity in Tarchonanthus camphoratus Plant Using ISSR Markers in Taif, KSA
}

\author{
Hatim Matouq Alyasi ${ }^{1, ~ *, ~ R a h m a h ~ N a s s e r ~ A l q t h a n i n ~}{ }^{2}$ \\ ${ }^{1}$ Biological Science, Taif Unoversity, Taif, Saudi Arabia \\ ${ }^{2}$ Biological Science, King Khalid University, Abha, Saudi Arabia
}

Email address:

htm333@hotmail.com (H. M. Alyasi)

*Corresponding author

\section{To cite this article:}

Hatim Matouq Alyasi, Rahmah Nasser Alqthanin. The Valuation of Genetic Diversity in Tarchonanthus camphoratus Plant Using ISSR Markers in Taif, KSA. American Journal of Agriculture and Forestry. Vol. 7, No. 6, 2019, pp. 277-281. doi: 10.11648/j.ajaf.20190706.15

Received: September 1, 2019; Accepted: October 5, 2019; Published: November 8, 2019

\begin{abstract}
Genetic variation among T. camphoratus individual plant samples collected from Taif region, Saudi Arabia was assessed using inter-simple sequence repeat (ISSR) markers. Eleven ISSR primers were used to evaluate T. camphoratus samples. The number of polymorphic bands per primer varied from 5 to 16, with 10.3 bands per primer on average. Nei's genetic distance between T. camphoratus samples ranged from 0.03 to 0.94 . According to genetic similarity and intraspecific differentiation, the $15 \mathrm{~T}$. camphoratus were grouped into two main different clusters with about 0.67 genetic similarity. It was not possible to classify the samples according to their geographic origin, showing that there is no structure in the gene bank. Cluster analysis is indicating good resolution of genetic diversity in Tarchonanthus germplasm using ISSR markers. Our results indicate that ISSR can be useful for genetic diversity studies, to provide practical information for parental selection, biodiversity and to assist breeding and conservation strategies.
\end{abstract}

Keywords: Tarchonanthus camphoratus, Genetic Variability, Molecular Markers, Genetic Resources

\section{Introduction}

The genus Tarchonanthus belongs to the family Asteraceae, the subfamily Cichorioideae and the tribe Tarchonantheae. Tarchonanthus is one of the rare Astareceae genera that consist of a tree [1-3]. Additionally, it is dioecious, with male and female flowers located on different plants. The exact name is generally selected to designate some outstanding features of the plant. The name camphoratus refers to the robust odor of camphor that given off whilst the leaves are crumpled. Many parts of Tarchonanthus species are used medicinally [4, 5]. Infusions and distillates of the leaves and branches are used for intestinal trouble, belly pain, headache, toothache, allergies, bronchitis and inflammation [4, 6]. Until currently the genus Tarchonanthus contained two species, viz. T. camphoratus and $T$. trilobus .During his revision and study on $T$. camphoratus complex, Herman on [3] Tarchonanthus camphoratus documented five species: T. camphoratus, $T$. obovatus, T. littoralis, T. minor and T. parvicapitulatus.
Molecular markers were used in several plant breeding and in studies associated with the preservation of genetic resources. Molecular markers have established to be precious methods for documentation, identification and assessment of the genetic assortment within and between cultivars. To meet the requirement for effective, precise, and fast documentation for genus Tarchonanthus and/or other plants, numerous molecular marker systems as RAPD [7, 8], ISSRs [9], and simple sequence repeats (SSRs) has been used effectively for molecular characterizion of several plants [9, 10]. Among them, ISSR has been conveyed as a fast, reproducible, and reasonably-priced fingerprinting method based totally on the difference observed inside the regions among microsatellites [10-12]. Amongst the various DNA marker classifications, ISSR is acquisition acceptance for its advantage over other dominant DNA marker systems like RAPD for higher polymorphism and improved marker resolvability [13]. The marker technique has been effectively working in genetic assortment analysis and fingerprinting of some crop species [14-16]. The current research is considering the first molecular fingerprinting examination of the locally grown $T$. 
camphoratus in Taif governorate using ISSR markers. The aims of the research can be concise as: 1) to assess the capacity of ISSR technique to discover the extent of assortment present in samples of Saudi Arabia $T$. camphoratus plant, and 2) to realize the genetic relationships amongst these genotypes for breeding studies of $T$. camphoratus.

\section{Materials and Methods}

\subsection{Plant Material and DNA Isolation}

A complete Fifteen individual plant samples of Tarchonanthus camphoratus gathered from Taif areas, Saudi Arabia, had been taken into consideration in the present research. From each genotype, the total genomic DNA was isolated from young leaves of grapevine plants using DNA Promega Kit DNeasy Blood \& Tissue (Valencia, CA, USA) according to the instructions of the manufacturer.

\subsection{ISSR-PCR Amplification}

PCR amplification of ISSR were completed as previously stated [13]. Amplified DNA fragments have been examined via $1.5 \%$ agarose gel electrophoresis. The gels were stained and visualized with the useful resource of UV illumination and then photographed by means of the usage of a Bio-Rad Gel Doc 2000 tool. The C1000TM Thermo Cycler device, Bio-Rad Germany, was used for the amplification of the plant genomic DNA template. The program condition was beneath the conditions associated with denaturation at ninety-four Celsius for five min; forty cycles of denaturation at ninetyfour Celsius for $30 \mathrm{Sec}$, primer annealing at fifty Celsius for $60 \mathrm{sec}$ and primer extension at seventy-two Celsius for 2.5min. Finally, one more stem for addition extension step at seventy-tow Celsius for $7 \mathrm{~min}$. The PCR products have been analyzed via $1.5 \%$ agarose gel electrophoresis. Next, the results were stained with ethidium bromide $(5 \mu \mathrm{g} / \mathrm{ml})$ and envisaged by UV illumination, at that time, the results were photographed by a Bio-Rad Gel Doc 2000 device.

Table 1. ISSR Primers used in study of genetic variation among $T$. camphoratus samples.

\begin{tabular}{ll}
\hline Primers Name & Primers sequences 5'- \\
\hline ISSR-2 & GTG GTT GTG CTT GCC \\
ISSR-3 & ACC ATG GCT ACC ACC GGC \\
ISSR-4 & GCA SGT GTG CTC GCC \\
ISSR-9 & CAG CAC ACA CAC ACA CA \\
ISSR-10 & ACA ATG GCT ACC ACT ACC \\
ISSR-11 & AAG CAA TGG CTA CCA CCA \\
ISSR-12 & ACG ACA TGG CGA CCA ACG \\
ISSR-14 & ACG ACA TGG CGA CCA CGC \\
ISSR-18 & ACA CAC ACA CAC ACA CG \\
ISSR-19 & AGA GAG AGA GAG AGA GTT \\
ISSR-28 & GTG GTG GTG GTG GTG GTG \\
\hline
\end{tabular}

\subsection{Data Analysis}

The genetic relatives among plants were assessed by using Neighbour joined method of Jaccard's similarity coefficient.
Next, the dendrogram that showing the genetic assortment was built. The computations had been achieved via the program NTSYS-PC version 2.01 [17].

\section{Results}

\subsection{Polymorphism of ISSR Markers}

The results of the banding pattern of electrophoresis showed that the ISSR markers could demonstrate the medium level of diversity existing among the plant individuals. Consequently, the markers were functional for the 15 individual plant samples of Tarchonanthus camphoratus (Figures 1 and 2). PCR based molecular markers can play an important role in the analysis of genetic diversity in such species. Here, eleven ISSR primers were used and generated 113 bands ranging in length from 190 to 1950bp (Table 2 and Figures 1, 2). The total monomorphic pattern was $74.4 \%$, while, the total polymorphic pattern was with low percentage of $25.6 \%$. The maximum and minimum number of amplified bands were belonged to ISSR-11 and ISSR-4 that are produced 5 and 16 bands, respectively. The percentage of polymorphic bands was varied from $11.1 \%$ for ISSR-3 and ISSR-12 primers to $72.7 \%$ for ISSR-19 primer. The average band per primer was 10.3 and the average percentage of polymorphic bands was $25.6 \%$. PCR-based molecular markers can perform a significant part in the investigation of genetic diversity in such plant species.
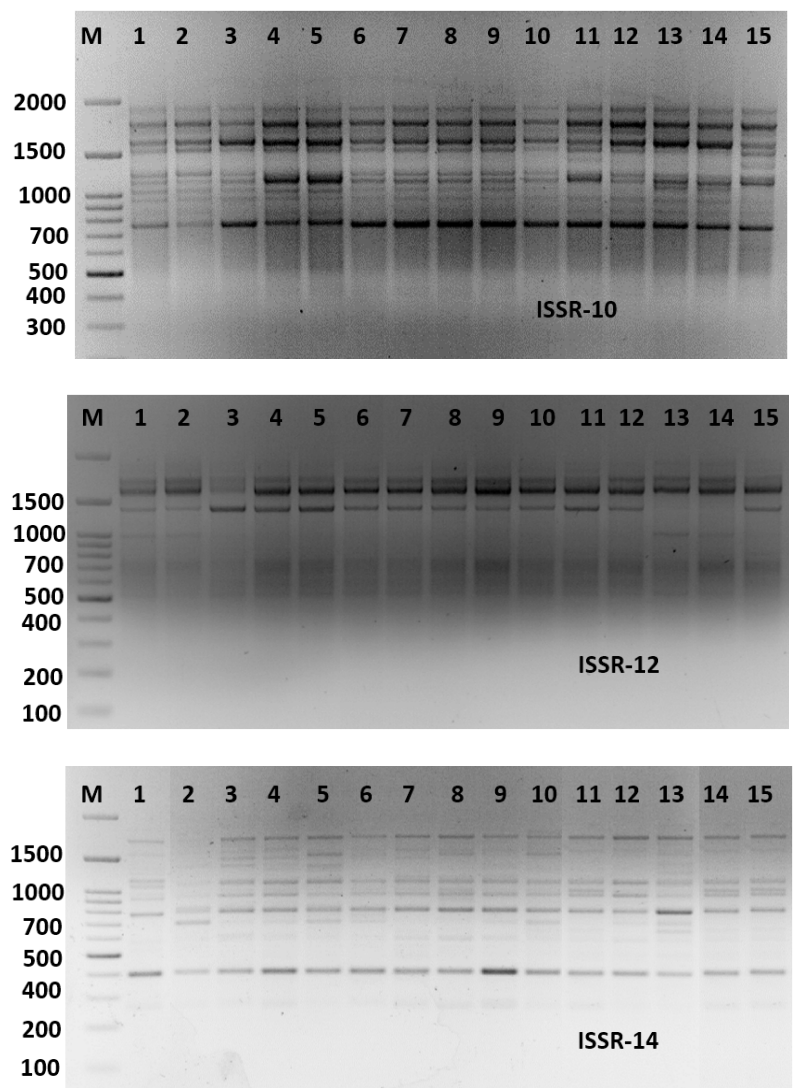

Figure 1. ISSR-PCR profile of 15 T. camphoratus samples generated with the respective ISSR primers: ISSR-10, ISSR-12, and ISSR-14. The first lane in each panel corresponds to 100-bp molecular weight markers. 

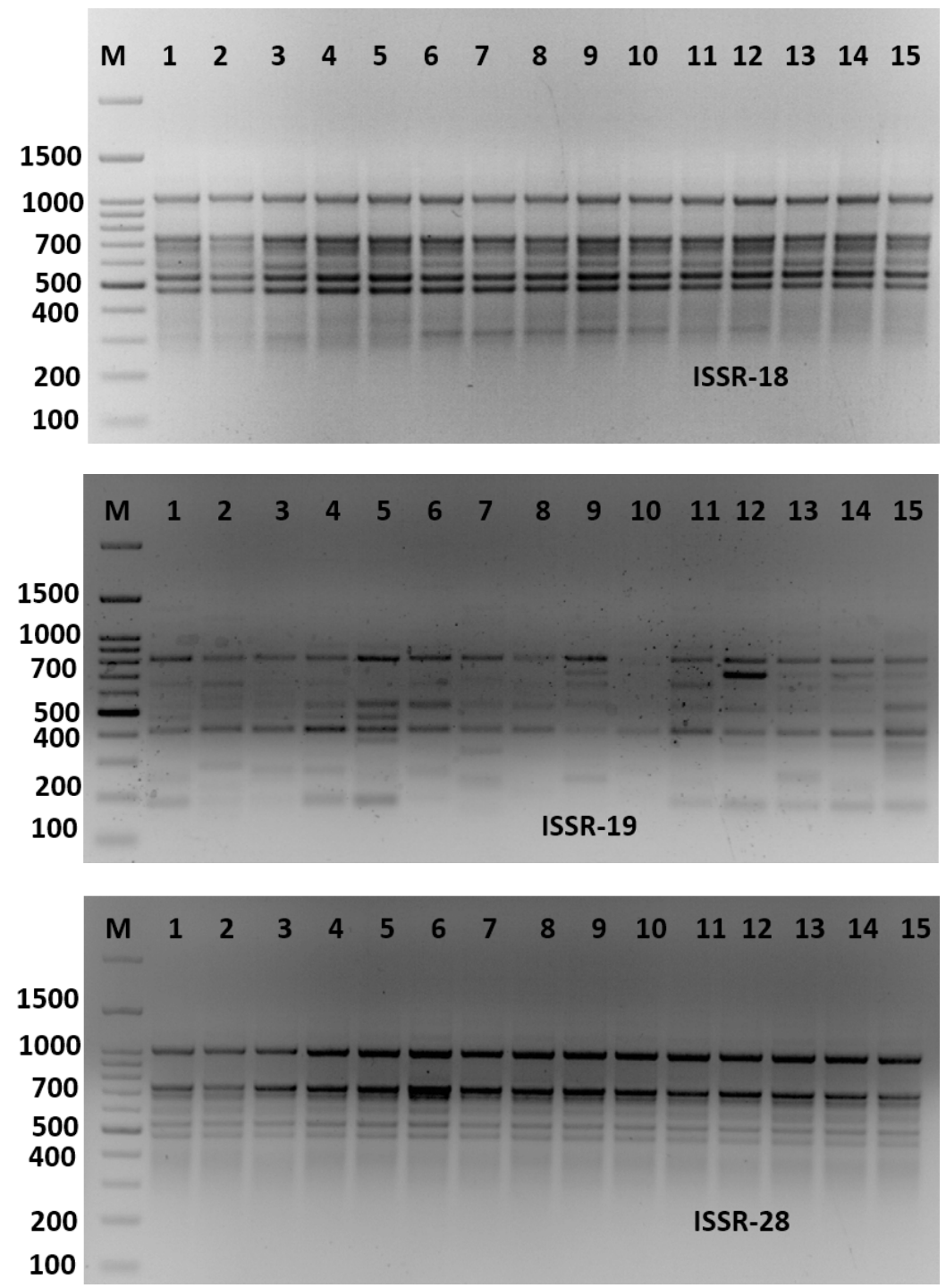

Figure 2. ISSR-PCR profile of 15 T. camphoratus samples generated with the respective ISSR primers: ISSR-18, ISSR-19, and ISSR-28. The first lane in each panel corresponds to 100-bp molecular weight markers.

Table 2. Eleven ISSR primers used to T. camphoratus plant samples, the total bands (TB), polymorphic bands (PB), monomorphic bands (MB), percentage of polymorphic bands $(P P B)$ and percentage of monomorphic bands $(P P B)$.

\begin{tabular}{llllll}
\hline Primers Name & TB & PB & MB & PPB (\%) & PMB (\%) \\
\hline ISSR-2 & 13 & 4 & 9 & 30.7 & 69.3 \\
ISSR-3 & 9 & 1 & 8 & 11.1 & 88.9 \\
ISSR-4 & 16 & 8 & 8 & 50.0 & 50.0 \\
ISSR-9 & 11 & 3 & 8 & 27.3 & 72.7 \\
ISSR-10 & 11 & 2 & 9 & 18.2 & 81.8 \\
ISSR-11 & 5 & 0 & 5 & 0.0 & 100 \\
ISSR-12 & 9 & 1 & 8 & 11.1 & 88.9 \\
ISSR-14 & 12 & 2 & 10 & 16.7 & 83.3 \\
ISSR-18 & 8 & 0 & 8 & 0.0 & 100 \\
ISSR-19 & 11 & 8 & 3 & 72.7 & 27.3 \\
ISSR-28 & 8 & 0 & 8 & 0.0 & 100 \\
Total & 113 & 29 & 84 & 25.6 & 74.4 \\
\hline
\end{tabular}

\subsection{Phylogeny Analysis of ISSR Marker}

As the result of genetic similarity and intraspecific differentiation, the 15-plant individual of $T$. camphoratus were assembled into two major clusters with about 0.67 genetic similarity (Table 3 and Figure 3). Interestedly, the minor cluster has two plant only plant sample-1 and plant sample-2. While, the second major cluster grouped into two sub-cluster that contained the other 13 plants with $71 \%$ similarity (Figure 3). 


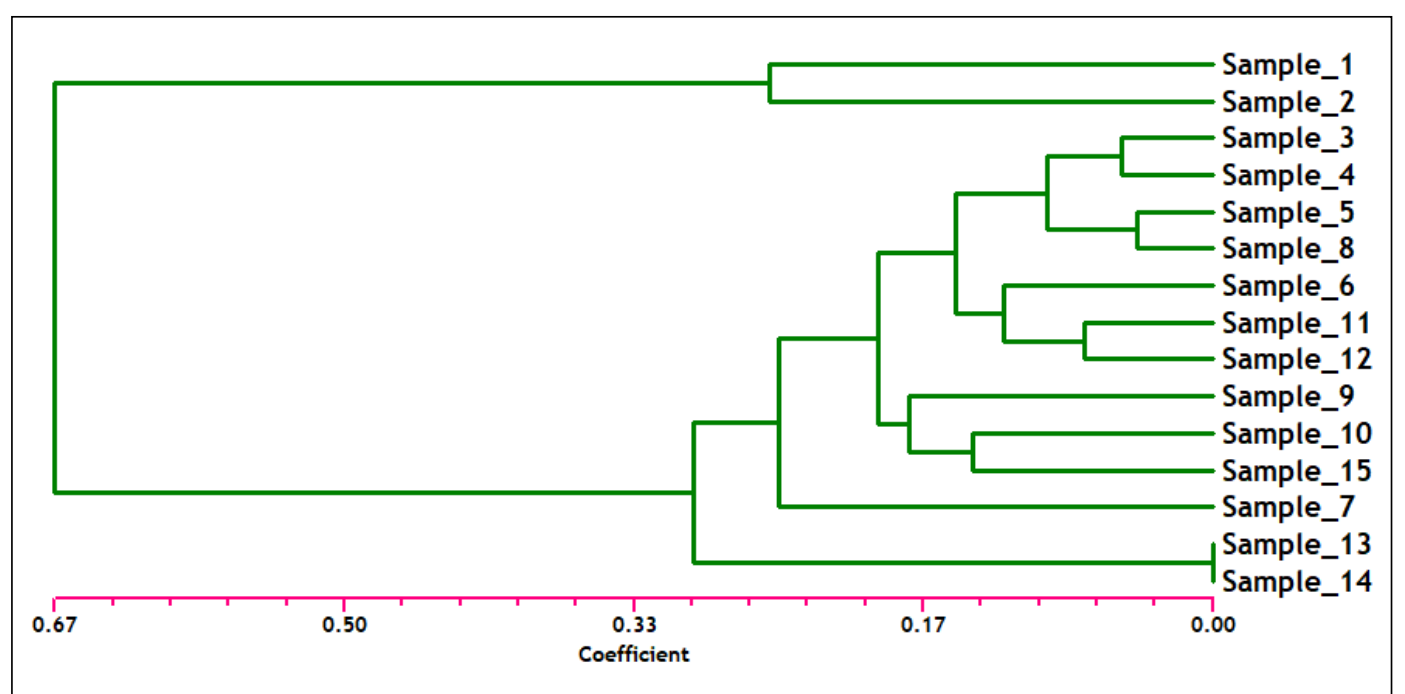

Figure 3. Dendrogram showing relationship of 15 individual plant samples of 15 T. camphoratus based on eleven ISSR marker using Jaccard's similarity coefficient.

Table 3. The genetic distance and similarity matrix between 15 individual samples of T. camphoratus.

\begin{tabular}{|c|c|c|c|c|c|c|c|c|c|c|c|c|c|c|c|}
\hline S. & 1 & 2 & 3 & 4 & 5 & 6 & 7 & 8 & 9 & 10 & 11 & 12 & 13 & 14 & 15 \\
\hline 1 & 0 & & & & & & & & & & & & & & \\
\hline 2 & 0.255 & 0 & & & & & & & & & & & & & \\
\hline 3 & 0.304 & 0.608 & 0 & & & & & & & & & & & & \\
\hline 4 & 0.356 & 0.66 & 0.052 & 0 & & & & & & & & & & & \\
\hline 5 & 0.447 & 0.752 & 0.143 & 0.143 & 0 & & & & & & & & & & \\
\hline 6 & 0.558 & 0.558 & 0.708 & 0.218 & 0.153 & 0 & & & & & & & & & \\
\hline 7 & 0.693 & 0.948 & 0.304 & 0.223 & 0.196 & 0.27 & 0 & & & & & & & & \\
\hline 8 & 0.404 & 0.708 & 0.1 & 0.047 & 0.043 & 0.095 & 0.153 & 0 & & & & & & & \\
\hline 9 & 0.693 & 0.948 & 0.304 & 0.223 & 0.196 & 0.153 & 0.223 & 0.153 & 0 & & & & & & \\
\hline 10 & 0.404 & 0.708 & 0.218 & 0.153 & 0.138 & 0.2 & 0.27 & 0.095 & 0.153 & 0 & & & & & \\
\hline 11 & 0.524 & 0.829 & 0.22 & 0.168 & 0.077 & 0.12 & 0.273 & 0.12 & 0.168 & 0.12 & 0 & & & & \\
\hline 12 & 0.524 & 0.829 & 0.22 & 0.168 & 0.077 & 0.12 & 0.273 & 0.12 & 0.273 & 0.215 & 0.074 & 0 & & & \\
\hline 13 & 0.558 & 0.558 & 0.558 & 0.558 & 0.558 & 0.996 & 0.351 & 0.27 & 0.244 & 0.318 & 0.404 & 0.2 & 0 & & \\
\hline 14 & 0.558 & 0.996 & 0.351 & 0.27 & 0.244 & 0.318 & 0.404 & 0.2 & 0.404 & 0.318 & 0.2 & 0.404 & 0 & 0 & \\
\hline 15 & 0.602 & 0.997 & 0.261 & 0.196 & 0.182 & 0.244 & 0.314 & 0.138 & 0.196 & 0.138 & 0.164 & 0.259 & 0.138 & 0.138 & 0 \\
\hline
\end{tabular}

\section{Discussion}

The use of molecular markers was pointing to display fast and consistent discrimination of genetic relatives of $T$. camphoratus in Taif region, Saudi Arabia. In the present study, DNA fingerprinting data generated by using ISSR marker was found to be efficient to distinguish different $T$. camphoratus individual samples. In this case, a set of minimum number of primers are required to be selected for the varietal identification and to select a set with minimum number of primers, it is important to consider level of marker polymorphism $[9,11]$. In case of ISSR markers, total genetic polymorphism of $25.6 \%$ was observed, showing that ISSR markers have low potential polymorphisms compared to SCoT marker in discriminating in some plant cultivars [14, 18]. On other hand, Schanzer and Vagina [19] reported that the total polymorphism amongst five Rosa varieties by using six ISSR primers were $90.6 \%$. It was interesting to know the correlation among percent polymorphism and attributes of the markers for sequence motifs $[9,20]$.
Eventually, ISSR molecular markers method is a smooth to perform, high float-through technique, probably will characterize it rather approach for RAPD method and higher reproducibility due to the elevated annealing temperatures. The mainly appealing role of ISSR assessment is its flexibility in the view of experimental layout, wherein the variety of generated amplicons may be optimized by altering the number of the core repeat units and anchoring bases [13, $21,22]$. Therefore, for its excessive simplicity, ISSR investigation must be a stand by desire for genome mapping or gene tagging and marker assisted selection. The latter exploitation and further research studies might be substantial for the simple basic and applied research especially on $T$. camphoratus and expand the information of microsatellite conservation and evolution of $T$. camphoratus especially in Saudi Arabia.

\section{Conclusion}

Tarchonanthus camphoratus, is a strongly aromatic shrub found growing in the hillsides between $1200-2500 \mathrm{~m}$ in KSA. 
Traditionally, its aromatic leaves are important for medical uses such as wounds and infections. This makes it a potentially important species for medical production for many diseases. in Taif province T. camphoratus constitutes a rich source of biodiversity and conservation and utilization requires a good knowledge on its genetic varatian. This may help for understanding the response of this species to climate changes as well as the mechanisms of its local adaptation. The study showed that ISSR is useful for genetic diversity in T. camphoratus, and indicated low potential of polymorphisms. There is therefore the need to further study, identify and preserve a broad genetic diversity in $T$. camphoratus. The findings of this study are therefore recommendable to all that working in decision maker for conservation of plant in Saudi Arabia.

\section{References}

[1] Acocks JPH, 1988. Veld types of South Africa. Edn. 3. Memoirs of the Botanical Survey of South Africa: 57.

[2] Pope GV, 1992. Compositae. Flora Zambesiaca 6: 9-11.

[3] Herman PPJ, 2002. Revision of the Tarchonanathus camphoratus complex (Asteraceae- Tarchonantheae) in Southern Africa. Bothalia 32: 21-28.

[4] Huyssteen M, Milne PJ, Campbell EE, van de Venter M, 2011. Antidiabetic and cytotoxicity screening of five medicinal plants used by traditional African health practitioners in the Nelson Mandela Metropole, South Africa. African Journal of Traditional, Complementary and Alternative Medicines, 8: 150-156.

[5] Njogu MK, Josphat CM, Marcel K, Reto B, Thomas JS, 2018. Antiprotozoal Sesquiterpene Lactones and Other Constituents from Tarchonanthus camphoratus and Schkuhria pinnata. Journal of Natural Products 81 (1): 124-130.

[6] Van-Vuuren SF, Viljoen AM, 2009. Interaction between the non-volatile and volatile fractions on the antimicrobial activity of Tarchonanthus camphoratus. South African Journal of Botany, 75: 505-509.

[7] Millan T1, Osuna F, Cobos S, Torres AM, Cubero JI, 1996. Using RAPDs to study phylogenetic relationships in Rosa. Theor Appl Genet., 92 (2): 273-7. doi: 10.1007/BF00223385.

[8] Atienza SG, Torres AM, Millan T, Cubero J I, 2005. Genetic diversity in Rosa as revealed by RAPDs, Agric Conspec Sci, 70: $75-85$.

[9] Crespel L, Pernet A, Le Bris M, Gudin S, Hibrand Saint Oyant L, 2009. Application of ISSRs for cultivar identification and assessment of genetic relationships in rose. Plant Breeding 12: 501-506.

[10] Zhang LH, Byrne DH, Ballard RE, Rajapakse S, 2006.
Microsatellite marker development in rose and its application in tetraploid mapping. J Am Soc Hortic Sci 131: 380-387.

[11] Golkar P, Arzani A, Rezaei AM, 2011. Genetic variation in safflower (Carthamus tinctorious L.) for seed quality-related traits and intersimple sequence repeat (ISSR) markers. Int J Mol Sci 12: 2664-2677.

[12] Nadeem M, Wang X, Akond M, Awan FS, Riaz A, Younis A, 2014. Hybrid identification, morphological evaluation and genetic diversity analysis of Rosa x hybrida by SSR markers. Australian Journal of Crop Science 8: 183-190.

[13] Hassan MM, Gaber A, El-Hallous E, 2014. Molecular and Morphological Characterization of Trichoderma harzianum from different Egyptian Soils. Wulfenia Journal 21: 80-96.

[14] Luo C, He XH, Chen H, Ou SJ, Gao MP, 2010. Analysis of diversity and relationships among mango cultivars using Start Codon Targeted (SCoT) markers. Biochem. Syst. Ecol. 38: $1176-1184$.

[15] Mulpuri S, Muddanuru T, Francis G, 2013. Start codon targeted (SCoT) polymorphism in toxic and non-toxic accessions of Jatropha curcas L. and development of a codominant SCAR marker. Plant Sci., 207: 117-127.

[16] Xiong F, Zhong R, Han Z, Jiang J, He L, Zhuang W, Tang R, 2011. Start codon targeted polymorphism for evaluation of functional genetic variation and relationships in cultivated peanut (Arachis hypogaea L.) genotypes. Mol. Biol. Rep., 38: 3487-3494.

[17] Rohlf FJ, 2000. NTSYS-PC numerical taxonomy and multivariate analysis system, Version 2.1. Exeter Software, Setauket, New York.

[18] Nasser A, Alia A, Mohamed A, Al-Fatimib R, Crouchc A, Denkertd, A, William N. S, Wessjohannd L., 2013. Antimicrobial, Antioxidant, and Cytotoxic Activities of the Essential Oil of Tarchonanthus camphoratus. Natural product communications. (5): 863-686.

[19] Schanzer IA, Vagina AV, 2007. ISSR (Inter Simple Sequence Repeat) Markers Reveal Natural Intersectional Hybridization in Wild Roses [Rosa (L.), Sect. Caninae (DC.) Ser. and Sect. Cinnamomeae (DC.) Ser.], Wulfenia, 14: 1-14.

[20] El-Assal S, El-Awady, M, El-Tarras A, Shehab G, 2014. Assessing the genetic relationship of Taif rose with some rose genotypes (Rosa sp.) Based on random amplified polymorphic DNA, inter simple sequence repeat and simple sequence repeat markers American Journal of Biochemistry and Biotechnology 10 (1): 88-98.

[21] Liu B, Wendel JF, 2001. Inter simple sequence repeat (ISSR) polymorphisms as a genetic marker system in cotton. Mol Ecol Notes 1: 205-208.

[22] Ullah S, Hasan Z, Aziz F, Amir I, Muhammad I, 2015. Diversity of Edible Fishes at Rhound Stream District Dir Lower, Khyber Pakhtunkhwa Pakistan. International Journal of Innovation and Applied Studies 10 (2): 466-472. 